\title{
Effect of dietary lipid sources on production performance of broilers
}

\author{
F.H. de Witt ${ }^{1 \#}$, S.P. Els ${ }^{1}$, H.J. van der Merwe ${ }^{1}$, A. Hugo ${ }^{2}$ and M.D. Fair ${ }^{1}$ \\ ${ }^{1}$ Department of Animal, Wildlife and Grassland Science, \\ ${ }^{2}$ Department of Microbial, Biochemical and Food Biotechnology, \\ P.O. Box 399, University of the Free State, Bloemfontein 9300, South Africa
}

\begin{abstract}
A study was conducted to determine the influence of different dietary lipid sources and inclusion levels on production performance of male broilers. Eight isoenergetic (15.1 MJ AME $/ \mathrm{kg} \mathrm{DM})$ and isonitrogenous (223 g CP/kg DM) diets were formulated, using high oleic sunflower oil (HO), sunflower oil (SO), fish oil (FO) and tallow (T) at a $30 \mathrm{~g} / \mathrm{kg}$ and $60 \mathrm{~g} / \mathrm{kg}$ dietary inclusion level. Eight hundred (800), dayold Ross 788 broiler males were randomly allocated to the eight treatments $(n=100)$ and were further subdivided into four replicates/treatment $(\mathrm{n}=25)$. All birds receive a standard commercial diet for the first 14 days, where-after the experimental diets were fed for 28 days. Feed intake and body weights were recorded weekly, while mortalities were recorded and dead birds weighed daily. Mortalities were brought into consideration during the calculation of average daily feed intake ( $\mathrm{g}$ feed/bird/day) and feed conversion ratio ( $\mathrm{g}$ feed/g body weight gain). Contrary to saturated fatty acids ( $\mathrm{T}$ ), the inclusion of unsaturated fatty acids $(\mathrm{HO}, \mathrm{SO}, \mathrm{FO})$ at a higher level $(60 \mathrm{~g} / \mathrm{kg})$ resulted in a significantly improved FCR. It seems that the optimum dietary inclusion level of saturated fatty acids is lower $(30 \mathrm{~g} / \mathrm{kg})$ than that of unsaturated sources.
\end{abstract}

Keywords: Ross 788, fatty acids, inclusion level, feed efficiency

${ }^{\#}$ Corresponding author. E-mail: dewittfh.sci@ufs.ac.za

\section{Introduction}

Current interest in the manipulation of the fatty acid profile of poultry meat and eggs is mainly due to the imbalances in human dietary intake of various fatty acids as well as consumer demand for "healthier" animal protein sources. The existing potential for the modification of dietary fatty acids has proved to be a viable method of value adding to poultry products since dietary fatty acids are absorbed and deposited in the body tissue without significant modification by birds (González-Esquerra \& Leeson, 2001). Scaife et al. (1994) and Lopez-Ferrer et al. (1999) reported that the lipid composition of broiler meat is modified according to the fatty acid profile of the dietary lipids sources within a week of feeding the diets.

The economy of using dietary fat is enhanced by an increased growth rate and improved feed efficiency. The positive effects of replacing dietary carbohydrates with lipid sources, especially under warm environmental temperatures, are mainly ascribed to a reduction in metabolic heat produced during digestion. In accordance with this, Zollitsch et al. (1997) and Crespo \& Esteve-Garcia (2001) suggested that the effects of dietary lipid source on the efficiency of utilization could be related to the degree of unsaturation of the source. This indicates that the digestibility and the metabolisable energy content differ between unsaturated and saturated lipid sources. However, literature is still gainsaid regarding the specific influences of dietary fatty acids generally used in the manipulation of carcass fatty acid profile as well as their dietary inclusion levels on production parameters of different sexes of broilers.

The aim of the study was to determine the influence of different available dietary lipid sources and inclusion levels on production performance of male broiler birds.

\section{Materials and Methods}

The experimental layout consists of a $4 \times 2$ factorial design with four dietary lipid sources and two inclusion levels. Eight hundred, day-old Ross 788 broiler males were obtained from a commercial hatchery and randomly allocated to the eight dietary treatments $(n=100 /$ treatment $)$. Each treatment was further subdivided into four replicates ( 25 birds/replicate). Birds received a commercial starter diet for the first 14 days, where-after the experimental diets were fed for 28 days until termination of the study. Eight isoenergetic (15.1 MJ AME/kg DM) and isonitrogenous (223 g CP/kg DM) experimental diets (mash form) 
were formulated by using high oleic sunflower oil (HO), sunflower oil (SO), fish oil (FO) and tallow (T) at a $30.0 \mathrm{~g} / \mathrm{kg}$ and $60.0 \mathrm{~g} / \mathrm{kg}$ dietary inclusion level respectively. The calculated chemical composition of the experimental diets is indicated in Table 1.

Table 1 The calculated chemical composition (g/kg DM) of the diets with a $30 \mathrm{~g} / \mathrm{kg}$ and $60 \mathrm{~g} / \mathrm{kg}$ lipid inclusion level

\begin{tabular}{ccc}
\hline & Dietary lipid inclusion level $(\mathrm{g} / \mathrm{kg})$ & 60 \\
\hline & 30 & 222.3 \\
Protein & 223.3 & 15.1 \\
AME $^{1}(\mathrm{MJ} / \mathrm{kg}$ DM) & 15.2 & 99.5 \\
Fat & 77.3 & 66.1 \\
Ash & 58.2 & 94.3 \\
NDF $^{2}$ & 81.7 & 51.8 \\
ADF $^{3}$ & 40.4 & 10.2 \\
Calcium & 10.1 & 7.6 \\
Phosphorus & 7.0 & 1.2 \\
Chlorine & 1.2 & 1.9 \\
Sodium & 1.9 & 8.6 \\
Potassium & 7.9 & 2.3 \\
Magnesium & 2.0 & 14.8 \\
Arginine & 14.3 & 9.3 \\
Isoleucine & 9.3 & 13.3 \\
Lysine & 13.4 & 6.2 \\
Methionine & 6.4 & 8.3 \\
Threonine & 8.4 & 2.7 \\
Tryptophan & 2.6 & 10.1
\end{tabular}

\footnotetext{
1 Apparent metabolizable energy (MJ/kg DM)

2 Neutral detergent fibre

3 Acid detergent fibre
}

Birds were reared inside a natural ventilated building on cement floor pens (12 birds $\left./ \mathrm{m}^{2}\right)$ using sawdust as bedding. Feed and water provision was on an ad libitum basis and an $18 \mathrm{~h}$ photoperiod was allowed throughout the experimental period. Feed intake (FI) and body weights were recorded weekly, while mortalities were recorded and weighed daily and brought into consideration during the calculation of FI (g/bird/day) and feed conversion ratio ( $\mathrm{g}$ feed/g body weight gain). Data collected during the 28 day experimental period was statistically analysed by means of a fully randomized factorial design. The SAS programme (SAS, 1999) was used to test for significant $(\mathrm{P}<0.05)$ differences between dietary treatments and Tukey's studentized range (HSD) and least square means tests were used to identify these differences.

\section{Results and Discussion}

The effect of different dietary lipid sources and inclusion levels on body weight gain (BWG), FI and FCR of male broiler chickens is indicated in Table 2. Contrary to Tukey's (HSD) test, analysis of variance showed that lipid source had no effect $(\mathrm{P}=0.1964)$ on FI, while increased lipid inclusion significantly $(\mathrm{P}=0.0041)$ reduced FI. These significant lower intake results seems to apply, however, only for the unsaturated fatty acid sources (HO, SO and FO). In fact, according to Tukey's least square means the highest FI occurred where a saturated fatty acid source, tallow (T), was included at $60 \mathrm{~g} / \mathrm{kg}$ in the diet. These 
Table 2 The effect of dietary lipid sources at different inclusion levels ( 30 and $60 \mathrm{~g} / \mathrm{kg}$ ) on body weight gain (BWG), feed intake (FI) and feed conversion ratio (FCR) of male broiler chickens between 15 and 42 days of age (Means)

\begin{tabular}{ccccccccccc}
\hline & \multicolumn{9}{c}{ Lipid source } & \multicolumn{5}{c}{ Significance (P) } \\
\hline Parameter & $\begin{array}{c}\text { Level } \\
(\mathrm{g} / \mathrm{kg})\end{array}$ & $\mathrm{HO}^{1}$ & \multicolumn{1}{c}{$\mathrm{SO}^{2}$} & \multicolumn{1}{c}{$\mathrm{FO}^{3}$} & $\mathrm{~T}^{4}$ & $\bar{X}$ & Source & Level & Interaction & $\mathrm{CV}^{5}$ \\
\hline $\mathrm{FI}^{7}$ & 30 & $152.26^{\mathrm{a} 1}$ & $150.77^{\mathrm{a} 1}$ & $151.35^{\mathrm{a} 1}$ & $147.54^{\mathrm{a} 1}$ & & 0.1964 & 0.0041 & 0.0014 & 2.50 \\
$(\mathrm{~g} / \mathrm{bird} /$ day $)$ & 60 & $145.02^{\mathrm{a} 1}$ & $143.09^{\mathrm{a} 1}$ & $143.25^{\mathrm{a} 1}$ & $153.87^{\mathrm{b} 1}$ & & & & & \\
$\mathrm{BWG}^{6}$ & 30 & 85.71 & 82.42 & 83.97 & 84.14 & 84.06 & 0.0996 & 0.4937 & 0.1958 & 2.42 \\
$(\mathrm{~g} / \mathrm{bird} /$ day $)$ & 60 & 84.79 & 84.37 & 82.67 & 86.41 & 84.56 & & & & \\
& $\bar{X}$ & 85.25 & 83.40 & 83.32 & 85.28 & & & & & \\
$\mathrm{FCR}^{8}$ & 30 & $1.74^{\mathrm{ab} 1}$ & $1.80^{\mathrm{a} 1}$ & $1.77^{\mathrm{ab} 1}$ & $1.72^{\mathrm{b} 1}$ & & 0.1731 & $<0.0001$ & $<0.0001$ & 1.51 \\
$(\mathrm{~g} / \mathrm{g})$ & 60 & $1.68^{\mathrm{a} 2}$ & $1.67^{\mathrm{a} 2}$ & $1.71^{\mathrm{ab} 2}$ & $1.75^{\mathrm{b} 1}$ & & & & &
\end{tabular}

a, b Row means with different superscripts differ significantly $(\mathrm{P}<0.05)$ within parameter means.

1,2 Column means with different superscripts differ significantly $(\mathrm{P}<0.05)$ within parameter means.

1 High oleic sunflower oil.

2 Sunflower oil.

3 Fish oil.

4 Tallow.

5 Coefficient of variation (\%).

6 Body weight gain (g / bird / day).

7 Feed intake (g/ bird / day).

8 Feed conversion ratio ( $\mathrm{g}$ feed / $\mathrm{g}$ body weight gain).

findings explained the significant $(\mathrm{P}=0.0014)$ source $\mathrm{x}$ inclusion level interaction that occurred. Since the experimental diets were isoenergetic and isonitrogenous, the lower FI caused by the unsaturated fatty acids at a higher inclusion level suggested that these fatty acids fulfil the energy requirements of the birds better, which could be ascribed to a more efficient digestion of these types of fats (Zollitsch et al., 1997). In accordance with the results of the present study, Villaverde et al. (2004) indicated that the average daily feed intake of broilers decreased $(P<0.05)$ with an increase in the degree of unsaturated fatty acids. Crespo \& Esteve-Garcia (2001) also reported that FI decreased $(\mathrm{P}<0.001)$ with an increase in dietary fat and concluded that FI and feed efficiency (FE) were affected by different types of fats.

From Table 2 it is further evident that neither dietary lipid source nor inclusion level had any effect on body weight gain of birds during the experimental period. These results are in agreement with Crespo \& Esteve-Garcia (2001) who also reported that different dietary fatty acids had no effect on body weight gain.

The lower FI of unsaturated fatty acid sources (HO, SO, FO) resulted in a better FCR at a higher lipid inclusion level (60 g/kg). Results of Zollitsch et al. (1997), Sanz et al. (2000a), Crespo \& Esteve-Garcia (2001) and Villaverde et al. (2004) indicated that an increase in the degree of unsaturation of dietary lipid sources resulted in an increased digestibility thereof and a consequent improvement of FE. Sanz et al. (2000a; b) and Chen \& Chiang (2005) stated that the energy available from unsaturated fat can be more readily used for metabolic purposes than that from saturated fat sources due to the faster rate in $\beta$-oxidation and the reduced endogenous fatty acid synthesis of unsaturated fatty acids. It also seems that young chicks absorbed unsaturated fatty acids better than saturated fatty acids (Chen \& Chiang, 2005), most probably due to their limited bile production capacity which hampers the digestion of saturated fatty acids. Results from the present study suggest that the optimum dietary inclusion level of saturated fatty acids is lower than that of unsaturated sources, due to digestion and metabolization differences between sources. Therefore, nutritionists need to consider the source $\mathrm{x}$ inclusion level interactions when formulating diets to manipulate the fat component of broiler carcasses and/or during the formulation of energy dense diets. 


\section{Conclusions}

These results suggested that contrary with saturated fatty acids $(T)$, the inclusion of unsaturated fatty acids (HO, SO, FO) at a higher level $(60 \mathrm{~g} / \mathrm{kg})$ would result in an improved FCR. Therefore, the optimum dietary inclusion level of saturated fatty acids $(\mathrm{T})$ seems to be lower $(30 \mathrm{~g} / \mathrm{kg})$ than those of unsaturated sources.

\section{References}

Chen, H.Y. \& Chiang, S.H., 2005. Effect of dietary polyunsaturated/saturated fatty acid ratio on heat production and growth performance of chicks under different ambient temperature. Anim. Feed Sci. Technol. 120, 299-308.

Crespo, N. \& Esteve-Garcia, E., 2001. Dietary fatty acid profile modifies abdominal fat deposition in broiler chickens. Poult. Sci. 80, 71-78.

González-Esquerra, R. \& Leeson, S., 2001. Alternatives for enrichment of eggs and chicken meat with omega-3 fatty acids. Can. J. Anim. Sci. 81, 295-305.

Lopez-Ferrer, S., Baucells, M.D., Barroeta, A.C. \& Grashorn, M.A., 1999. N-3 enrichment of chicken meat using fish oil: Alternative substitution with rapeseed and linseed oils. Poult. Sci. 78, 356-365.

Sanz, M., Flores, A. \& Lopez-Bote, C.J., 2000a. The metabolic use of energy from dietary fat in broilers is affected by fatty acid saturation. Br. Poult. Sci. 41, 61-66.

Sanz, M., Lopez-Bote, C.J., Menoyo, D. \& Bautista, J.M., 2000b. Abdominal fat deposition and fatty acid synthesis are lower and $\beta$-oxidation is higher in broiler chickens fed diets containing unsaturated rather than saturated fat. J. Nutr. 130, 3034-3037.

SAS, 1999. SAS ${ }^{\circledR}$ User's Guide. Version 6.12. SAS Institute Inc. Cary, N.C., USA.

Scaife, J.R., Moyo, J., Galbraith, H., Michie, W. \& Campbell, V., 1994. Effects of different dietary supplemental fats and oils on the tissue fatty acid composition and growth of female broiler. Br. Poult. Sci. 35, 107-118.

Villaverde, C., Cortinas, L., Barroeta, A.C., Martín-Orúe S.M. \& Baucells, M.D., 2004. Relationship between dietary unsatturation and Vitamin E in poultry. J. Anim. Physiol. and Anim. Nutr. 88, 143-149.

Zollitsch, W., Knaus, W., Aichinger, F. \& Lettner, F., 1997. Effects of different dietary fat sources on performance and carcass characteristics of broilers. Anim. Food. Sci. Technol. 66, 63-73. 